\title{
GABAergic Precursor Transplantation into the Prefrontal Cortex Prevents Phencyclidine-Induced Cognitive Deficits
}

\author{
Daisuke H. Tanaka, ${ }^{1 \star}$ Kazuya Toriumi, ${ }^{2,3 *}$ Ken-ichiro Kubo, ${ }^{1}$ Toshitaka Nabeshima, ${ }^{2,3}$ and Kazunori Nakajima ${ }^{1}$ \\ ${ }^{1}$ Department of Anatomy, Keio University School of Medicine, Shinjuku-ku Tokyo 160-8582, Japan, and 2Department of Chemical Pharmacology, Graduate \\ School of Pharmaceutical Sciences, and ${ }^{3}$ Comparative Cognitive Science Institutes, Meijo University, Tenpaku-ku, Nagoya, Aichi 468-8503, Japan
}

Phencyclidine (PCP) is a noncompetitive NMDA receptor antagonist, and it induces schizophreniform cognitive deficits in healthy humans and similar cognitive deficits in rodents. Although the PCP-induced cognitive deficits appear to be accompanied and possibly caused by dysfunction of GABAergic inhibitory interneurons in the prefrontal cortex (PFC), the potential benefit(s) of GABAergic interneuron manipulations on PCP-induced cognitive deficits remains unexplored. In this study we show that when embryonic medial ganglionic eminence (MGE) cells, many of which differentiate into cortical GABAergic interneurons in situ, were grafted into the medial PFC (mPFC) of neonatal mice, they differentiated into a specific class of GABAergic interneurons and became functionally integrated into the host neuronal circuitry in adults. Prior MGE cell transplantation into the mPFC significantly prevented the induction of cognitive and sensory-motor gating deficits by PCP. The preventive effects were not reproduced by either transplantation of cortical projection neuron precursors into the mPFC or transplantation of MGE cells into the occipital cortex. The preventive effects of MGE cell transplantation into the MPFC were accompanied by activation of callosal projection neurons in the mPFC. These findings suggest that increasing GABAergic interneuron precursors in the PFC may contribute to the development of a cell-based approach as a novel means of modulating the PFC neuronal circuitry and preventing schizophreniform cognitive deficits.

\section{Introduction}

Noncompetitive NMDA receptor antagonists, including phencyclidine (PCP), evoke schizophreniform cognitive deficits in healthy humans (Javitt and Zukin, 1991) and similar cognitive deficits in rodents (Mouri et al., 2007a). The cognitive deficits induced by the NMDA receptor antagonists are associated with altered rhythmic activities (Sebban et al., 2002; Kiss et al., 2011) and alterations of projection neuron activity in the prefrontal cortex (PFC) (Jackson et al., 2004; Kargieman et al., 2007). The alterations of projection neuron activity appear to be preceded by (Homayoun and Moghaddam, 2007) and to be reproduced by (Sohal et al., 2009; Korotkova et al., 2010) decreased activity of fast-spiking parvalbumin (PV)-positive inhibitory GABAergic

\footnotetext{
Received June 4, 2011; revised July 20, 2011; accepted Aug. 10, 2011

Author contributions: D.H.T., K.T., K.-i.K., and T.N. designed research; D.H.T. and K.T. performed research; D.H.T. and K.T. analyzed data; D.H.T., K.T., T.N., and K.N. wrote the paper.

This work was supported by the Strategic Research Program for Brain Sciences ("Understanding of molecular and environmental bases for brain health"), Global COE (Centers of Excellence) program, Academic Frontier Project for Private Universities (2007-2011), the Ministry of Education, Culture, Sports, Science, and Technology of Japan, the Japan Society for the Promotion of Science, Research on Regulatory Science of Pharmaceutical and Medical Devices, the Ministry of Health, Labour and Welfare, the Promotion and Mutual Aid Corporation for Private Schools of Japan, and the Circle for the Promotion of Science and Engineering. We thank Dr. H. Furukawa for synthesizing the PCP, Dr. A. M. Goffinet for providing the anti-Reelin antibody (G10), and Dr. A. Mouri for helpful discussions.

${ }^{*}$ D.H.T. and K.T. contributed equally to this work.

The authors declare no competing financial interests.

Correspondence should be addressed to either of the following: Toshitaka Nabeshima, Department of Chemical Pharmacology, Meijo University, 150 Yagotoyama, Tenpaku-ku, Nagoya, Aichi 468-8503, Japan, E-mail: tnabeshi@meijo-u.ac.jp; or Kazunori Nakajima, Department of Anatomy, Keio University School of Medicine, 35 Shinanomachi, Shinjuku-ku, Tokyo 160-8582, Japan, E-mail: kazunori@z6.keio.jp.

DOI:10.1523/JNEUROSCI.2786-11.2011

Copyright $\odot 2011$ the authors $\quad 0270-6474 / 11 / 3114116-10 \$ 15.00 / 0$
}

interneurons in the PFC. A majority of cortical GABAergic interneurons are classified into either PV-positive interneurons or somatostatin (SST)-positive interneurons (Kawaguchi and Kubota, 1997). PV-positive interneurons are involved in cortical rhythmogenesis (Klausberger et al., 2005; Fuchs et al., 2007; Cardin et al., 2009; Sohal et al., 2009; Korotkova et al., 2010), and SST-positive interneurons may also be involved in cortical rhythmogenesis, because they are extensively electrically coupled into networks that robustly synchronize their spiking activity (Gibson et al., 1999, 2005) in the theta range $(4-7 \mathrm{~Hz})$, which induces synchronized IPSPs in neighboring projection neurons (Beierlein et al., 2000). Thus, PCP may alter the rhythmic activity of projection neurons in the PFC, and that may be related to the cognitive deficits through the dysfunction of PV-positive interneurons and/or SST-positive interneurons in the PFC. However, the potential benefit(s) of manipulations of these interneurons in the PFC on PCP-induced cognitive deficits remains unexplored.

During the development of the mouse cortex, most PVpositive interneurons and SST-positive interneurons are generated in the medial ganglionic eminence (MGE) of the embryonic ventral forebrain (Lavdas et al., 1999; Xu et al., 2004; Fogarty et al., 2007). A majority of SST-positive interneurons secrete Reelin (Miyoshi et al., 2010), which enhances NMDA receptormediated signaling (Herz and Chen, 2006; Knuesel, 2010). When transplanted into the cortex of older animals, the young MGE cells disperse widely and differentiate into either PV-positive interneurons or SST-positive interneurons (Wichterle et al., 1999; Alvarez-Dolado et al., 2006; Baraban et al., 2009; Southwell et al., 
A

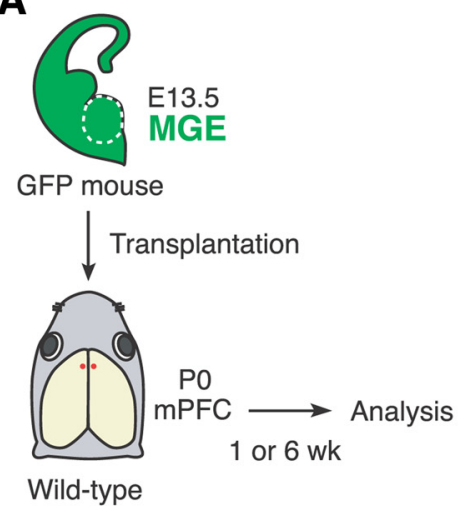

B 1 wk after transplantation GFP DAPI

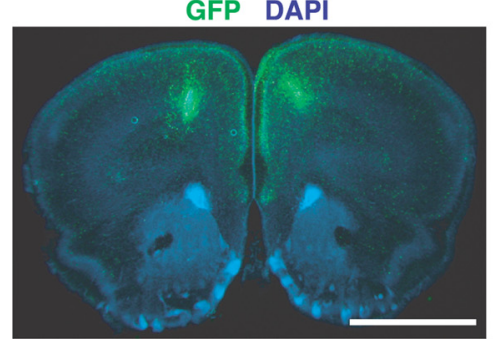

C

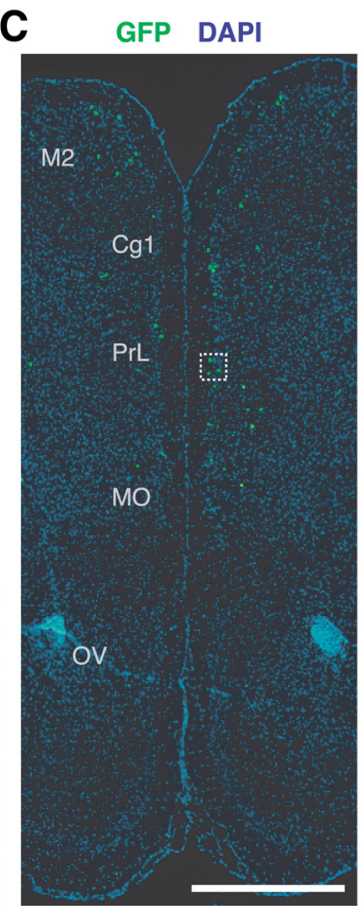

6 wk after transplantation

D

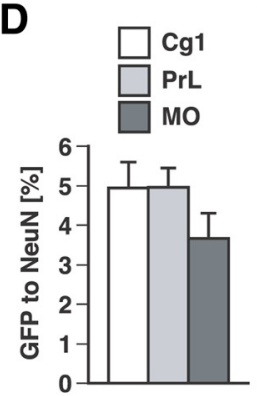

$\mathbf{E}$

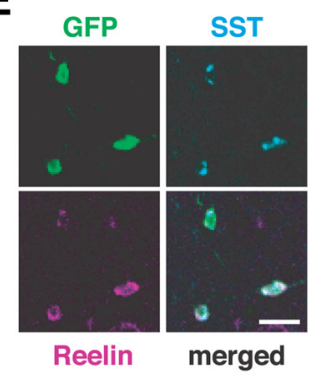

$\mathbf{F}$

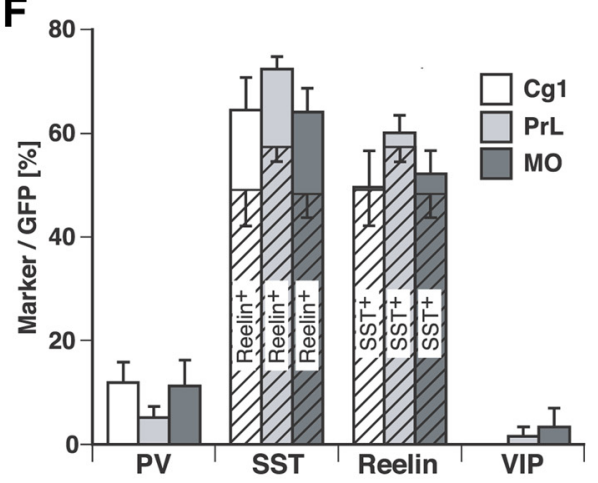

Figure 1. A majority of the MGE cells transplanted into the neonatal mPFC differentiated into an SST/Reelin-expressing class of GABAergic interneurons in adults. A, Schema of MGE dissection (region within the dashed white line in E13.5 GFP-expressing telencephalic coronal slices) and bilateral transplantation into the mPFC of P0 wild-type recipient mice (filled red circles) (dorsal view of a head). Transplanted cells were analyzed 1 week or 6 weeks after transplantation. B, C, Representative distribution of GFP-expressing cells (green) on coronal sections (100 $\mu \mathrm{m}$ thick in B, $8 \mu \mathrm{m}$ thick in $\boldsymbol{C}$ ) at the level of the prospective injection site at 1 week $(\boldsymbol{B})$ and 6 weeks $(\boldsymbol{C})$ after transplantation. $\boldsymbol{D}$, Ratio of the number of GFP-expressing cells to the number of NeuN-positive cells within the Cg1 (white bar) ( $n=311$ GFP-expressing cells, 6373 NeuN-positive cells), the PrL (light gray bar) ( $n=844$ GFP-expressing cells, 17,520 NeuN-positive cells), and the M0 (dark gray bar) ( $n=$ 1242 GFP-expressing cells, 35,591 NeuN-positive cells) at 6 weeks after transplantation ( $n=12$ hemispheres). There were no statistically significant differences between the regions. $\boldsymbol{E}$, Enlarged view of the boxed area in C. Coexpression of SST (light blue) and Reelin (magenta) in GFP-expressing cells in the PrL. The "merged" panel is a merged figure of the other three. $\boldsymbol{F}$, Calculation of the percentage of GFP-expressing cells expressing an interneuron subtype marker(s) within the C 1 ( white bars) ( $n=255$ GFP-expressing cells), the PrL (light gray bars) ( $n=497$ GFP-expressing cells) and the M0 (dark gray bars) ( $n=343$ GFP-expressing cells) at 6 weeks after transplantation ( $n=5-6$ hemispheres). Shaded bars indicate the percentage of GFP-expressing cells that are SST/Reelin-coexpressing cells. M2, Secondary motor cortex; OV, olfactory ventricle. Scale bars: $\boldsymbol{B}, 500 \mu \mathrm{m} ; \boldsymbol{C}, 1 \mathrm{~mm} ; \boldsymbol{E}, 20 \mu \mathrm{m}$.

2010). MGE cell transplantation increases GABA-mediated inhibition on host projection neurons and modulates host neuronal circuitry and its activity (Alvarez-Dolado et al., 2006; Baraban et al., 2009; Southwell et al., 2010; Zipancic et al., 2010). Their transplantation reduces seizures (Baraban et al., 2009; Zipancic et al., 2010), ameliorates motor deficits (Martínez-Cerdeño et al., 2010) and induces cortical plasticity (Southwell et al., 2010).

All of the above findings together raise the possibility that MGE cell transplantation into the PFC may modulate host medial PFC (mPFC) neuronal circuitry through GABA-mediated inhibition and/or Reelin-mediated signaling, which may then prevent the alteration of the rhythmic activity of projection neurons and the cognitive deficits induced by PCP. In the present study, we especially focused on an analysis of the expected final effect of MGE cell transplantation into the $\mathrm{MPFC}$, i.e., prevention of the induction of cognitive deficits by PCP.

\section{Materials and Methods}

\section{Animals}

Embryonic donor tissue was obtained by crossing ICR wild-type female mice with homozygous green fluorescent protein (GFP)-expressing C57BL/6-Tg(CAG-EGFP)C14-Y01-FM131Osb male mice (Okabe et al., 1997), in which essentially all cell types express GFP. Breeder and host ICR wild-type mice were obtained from SLC Japan. Littermates were used as controls in all comparison studies, including the c-Fos expression and behavioral studies. All animals intended for use in the behavioral studies were maintained on a $12 \mathrm{~h} \mathrm{light/dark} \mathrm{cycle} \mathrm{(lights} \mathrm{on} \mathrm{at} \mathrm{8:00} \mathrm{A.M.)}$ and given ad libitum access to food (CE2; Clea Japan Inc.). Noon on the day a vaginal plug was detected was recorded as embryonic day 0.5 (E0.5), and E19.5 was counted as postnatal day 0 (P0). All animal experiments were performed in accordance with the Guidelines for the Care and Use of Laboratory Animals of Keio University School of Medicine, the Guidelines for Animal Experiments of Meijo University Faculty of Pharmaceutical Sciences, and the Guiding Principles for the Care and Use of Laboratory Animals approved by the Japanese Pharmacological Society.

\section{Donor tissue dissection}

Approximate ventricular and subventricular zones of the MGE or rostromedial cortical wall, the presumptive region of the mPFC, of E13.5 GFP-expressing embryos were dissected in chilled Hanks' balanced salt solution devoid of calcium and magnesium (Sigma). Explants were mechanically dissociated into a single cell suspension in Leibovitz's L-15 medium (Invitrogen) containing DNase I (100 $\mu \mathrm{g} / \mathrm{ml}$; Sigma) by repeated pipetting with a $200 \mu \mathrm{l}$ tip (15-25 times). Dissociated cells were pelleted by centrifugation ( $5 \mathrm{~min}, 800 \mathrm{~g})$. Cell suspensions $\left(\sim 10^{6} \mathrm{cells} / \mu \mathrm{l}\right.$ in L-15 medium containing $100 \mu \mathrm{g} / \mathrm{ml}$ DNase I) were kept on ice until used.

\section{Cell transplantation}

The donor cell suspensions were front-loaded into beveled glass micropipettes ( $\sim 75 \mu \mathrm{m}$ caliber at the tip) (GD-1; Narishige). P0 host mice were anesthetized by chilling on ice, and they were then fixed in position under a stereomicroscope. The $x-y$ coordinates of the injection sites were estimated from the surface anatomy: for transplantation into the mPFC (Fig. $1 A$ ), the rostrocaudal level of the injection site was one fourth the dis- 
tance from the rostrocaudal level of the center of the eye to the rostrocaudal level of the lambdoid suture. The mediolateral level of the injection site was one eighth the distance from the mediolateral level of the center of the eye to the midline. The injection site was defined as the point of intersection between a line passing through the rostrocaudal level of the injection site and a line passing through the mediolateral level of the injection site in each hemisphere; for transplantation into the occipital cortex (see Fig. 3B), the rostrocaudal level of the injection site was half the distance from the rostrocaudal level of the lambdoid suture to the rostrocaudal level of the caudal edge of the cerebral cortex. The mediolateral level of the injection site was half the distance from the mediolateral level of the center of the eye to the midline. The injection site was defined as the point of intersection between a line passing through the rostrocaudal level of the injection site and a line passing through the mediolateral level of the injection site in each hemisphere. The $z$-coordinate of the injection sites was $\sim 0.9 \mathrm{~mm}$ below the skin surface for transplantation into the $\mathrm{mPFC}$ and $\sim 0.7 \mathrm{~mm}$ below the skin surface for transplantation into the occipital cortex. Approximately $10^{5}$ cells $(\sim 0.1 \mu \mathrm{l})$ were transcranially injected into the mPFC or occipital cortex of each hemisphere bilaterally (total of $2 \times 10^{5}$ cells per animal). Cell flow within the pipette during injection was confirmed visually during every injection. A similar volume of vehicle was injected into controls for the behavioral analysis. Vehicle injection is a standard control procedure for grafting studies and provides more reliable controls than injection of "dead" cells, which would cause toxic effects and exaggerate any positive graft effects under certain conditions (Modo et al., 2003). Immediately after the injections, the recipient mice were placed on a warm surface until they became active, and they were then returned to their mothers until they reached weaning age (4 weeks).

\section{Immunohistochemistry}

Animals were transcardially perfused with $4 \%$ paraformaldehyde (PFA) or $4 \%$ PFA containing $0.08 \%$ glutaraldehyde in phosphate buffer $(0.1 \mathrm{M}$, $\mathrm{pH}$ 7.4). The brains were removed, postfixed at $4^{\circ} \mathrm{C}$ for $2 \mathrm{~h}$ to overnight in the same fixatives, and washed with PBS (0.1 M, pH 7.4). For cryosectioning, brains were cryoprotected in $30 \%$ sucrose in $\mathrm{PBS}$ at $4^{\circ} \mathrm{C}$. Coronal sections were cut with a vibrating-blade microtome $(50-100 \mu \mathrm{m})$ (VT1000; Leica Microsystems) or a frozen sliding microtome $(8-10 \mu \mathrm{m})$ (CM3050 M; Leica Microsystems). The sections were incubated in PBS with $0.3 \%$ Triton X-100 and 5\% normal donkey serum (NDS) for $1-2 \mathrm{~h}$ at room temperature (RT) and then for $1-2 \mathrm{~d}$ at RT or for $2 \mathrm{~d}$ at $4^{\circ} \mathrm{C}$ in the primary antibody diluted in PBS with $0.3 \%$ Triton X-100 and $1 \%$ NDS. The primary antibodies used were as follows: chicken anti-GFP (1:500; Abcam), mouse anti-NeuN (1:50; Millipore), mouse anti-CNPase (1: 500; Abcam), rabbit anti-GFAP (1:1000; DAKO), rabbit anti-GABA (1: 1000; Sigma), mouse anti-PV (1:1000; Sigma); rabbit anti-PV (1:2000; Abcam), rat anti-SST (1:100; Millipore), mouse anti-Reelin (G10; 1:500; gift from Dr. André M. Goffinet, University of Louvain, Brussels, Belgium), rabbit anti-vasoactive intestinal polypeptide (VIP) (1:300; Immunostar), rabbit anti-c-Fos (1:500; Santa Cruz Biotechnology), mouse anti-Satb2 (1:50; Abcam), or rat anti-Ctip2 (1:500; Abcam). The sections were incubated for $1-3 \mathrm{~h}$ at RT in a secondary antibody diluted in $1 \%$ NDS in PBS. The secondary antibodies used were as follows: donkey DyLight488-conjugated anti-chicken IgY, donkey DyLight549- or TRITCconjugated anti-rabbit IgG, donkey Cy5-, DyLight549-, or TRITCconjugated anti-mouse IgG or donkey Cy5-conjugated anti-rat IgG (all at 1:100; all from Jackson ImmunoResearch). For nuclear staining, sections were incubated in 1\% 4,6-diamidino-2-phenylindole (DAPI) (Sigma) in PBS for 10-30 min at RT. Images were captured with a CCD camera (VB-7010; Keyence) attached to an epifluorescence microscope (BX60; Olympus) or with a confocal microscope (FV1000; Olympus).

\section{Quantification of transplanted cells}

$M G E$ cell transplantation into the $m P F C$. To estimate the number of surviving cells after MGE cell transplantation into the mPFC, we counted the number of cortical GFP-positive cells in every eighth coronal slice from brains at 6 weeks after transplantation. The total number of surviving MGE cells was calculated by multiplying the number counted by eight. The GFP-expressing cells in the prelimbic cortex (PrL) (Franklin and Paxinos, 2008) were examined for expression of NeuN, GABA, SST, CNPase, and GFAP, and they were counted manually to calculate the ratio of GFP/NeuN-double-positive cells to GFP-positive cells, the ratio of GFP/GABA-double-positive cells to GFP-positive cells, the ratio of GFP/CNPase-double-positive cells to GFP-positive cells, the ratio of GFP/GFAP-double-positive cells to GFP-positive cells, the ratio of GFP/ GABA-double-positive cells to GABA-positive cells, and the ratio of GFP/SST-double-positive cells to SST-positive cells. To examine the interneuron subtypes and the functional integration of the transplanted cells, the GFP-expressing cells in area 1 of the cingulate cortex (Cg1), the PrL, and the medial orbital cortex (MO) (Franklin and Paxinos, 2008) were examined for expression of several markers and were counted manually. To determine the ratio of the number of GFP-expressing cells or c-Fos-positive cells to the number of NeuN-positive cells in the Cg1, the PrL, and the MO (Franklin and Paxinos, 2008), the numbers of c-Fospositive and NeuN-positive cells in these regions were counted with $\mathrm{NIH}$ ImageJ software (version $1.40 \mathrm{~g}$ ), and the number of GFP-expressing cells was counted manually. To examine the cell-type of c-Fos-positive cells, the c-Fos-positive cells in the PrL and the MO (Franklin and Paxinos, 2008) were examined for expression of Satb2 and GFP manually and were counted with the NIH ImageJ software (version $1.40 \mathrm{~g}$ ).

Rostromedial cortex cell transplantation into the mPFC. The bright GFP-expressing cells with DAPI staining around the center of the cell in the Cg1, the PrL, and the MO (Franklin and Paxinos, 2008) were examined for expression of Satb2 and Ctip2 at 6 weeks after transplantation and were counted manually. Most GFP-expressing cells were clustered in the $\mathrm{Cg} 1$ and the PrL, the presumptive injection site, and essentially no GFP-expressing cells were found in the MO.

MGE cell transplantation into the occipital cortex. The GFP-expressing cells in the primary visual cortex (Franklin and Paxinos, 2008) were examined for expression of GABA, PV, and SST at 6 weeks after transplantation and were counted manually. Most GFP-expressing cells were found in the caudolateral cortex and the hippocampus, and essentially no cells were found in the mPFC.

The SEM in the histological analyses is attributable to the variability across different hemispheres.

\section{Behavioral analysis}

We decided on $\sim 6$ weeks after transplantation (P40-P47) as the optimal time to perform the behavioral tests in this study, because synaptic integration of MGE cells transplanted into neonatal mouse visual cortex has been demonstrated at approximately that time ( $\sim 36 \mathrm{~d}$ after transplantation) (Southwell et al., 2010) and because 6 weeks of age in mice appeared to largely correspond to mid-adolescence in humans (Spear, 2000), when the symptoms of schizophrenia usually are first manifested.

Novel enriched environment. The novel enriched environment consisted of a Plexiglas open field box $(30 \times 30 \times 35 \mathrm{~cm})$ whose floor was covered with sawdust, and two novel objects (half of a red plastic ball and a $100 \mathrm{ml}$ culture flask with a light green cap) were placed on the floor. The experimental mice were placed into the box individually and allowed to explore for $10 \mathrm{~min}$. Control mice continued to be housed in their home cage.

PCP administration. PCP hydrochloride was synthesized according to the method reported in the literature (Maddox et al., 1965) and checked for purity. PCP dissolved in saline was injected $(1 \mathrm{mg} / \mathrm{kg}$, s.c.) 6 weeks after transplantation, $30 \mathrm{~min}$ before the prepulse inhibition (PPI) test and the training session in the novel object recognition test (NORT). Controls were injected with an equal volume of vehicle (saline).

NORT. The NORT was conducted as described previously (Mouri et al., 2007b) with minor modifications. The experimental apparatus consisted of a Plexiglas open field box $(30 \times 30 \times 35 \mathrm{~cm})$ whose the floor was covered with sawdust. The test procedure consisted of three sessions: habituation, training, and retention. At 6 weeks after transplantation, each mouse was individually habituated to the box by allowing $10 \mathrm{~min}$ of exploration in the absence of any objects each day for 3 consecutive days (Day 1-3) (habituation session). On Day 4, two novel objects were symmetrically placed on the sawdust on the floor of the box, $8 \mathrm{~cm}$ from the walls. Each animal was allowed to explore the box for $10 \mathrm{~min}$, and the time spent exploring each object was recorded (training session). The objects 
were of different shapes and colors, but of similar sizes. Throughout the experiments, the objects were used in a counterbalanced manner in terms of their physical complexity and emotional neutrality. An animal was considered to be exploring an object when its head was facing the object or when an animal was sniffing an object at a distance of $<2 \mathrm{~cm}$ and/or was touching it with its nose. At the conclusion of the training session, the mouse was immediately returned to its home cage. On Day 5, $1 \mathrm{~d}$ after the training session, the animals were placed back into the same box with one of the familiar objects used in the training session and one novel object. They were allowed to explore freely for $5 \mathrm{~min}$ and the time spent exploring each object was recorded (retention session). Exploratory preference, the ratio of time spent exploring each of the two objects (training session) or the novel object (retention session) to the total amount of time spent exploring both objects, was used to assess cognitive function.

PPI test. PPI of the acoustic startle response was measured with an SR-LAB System (San Diego Instruments). The stimulus consisted of a 20 ms prepulse, a $100 \mathrm{~ms}$ delay, and then a $40 \mathrm{~ms}$ startle pulse. The intensity of the prepulse was 16 decibel $(\mathrm{dB})$ above the $70 \mathrm{~dB}$ background noise. The amount of prepulse inhibition was calculated as a percentage of the $120 \mathrm{~dB}$ acoustic startle response: $100-$ [(startle reactivity on prepulse + startle pulse)/startle reactivity on startle pulse] $\times 100$.

\section{Statistical analysis}

The Mann-Whitney $U$ test or paired $t$ test was used for comparisons between two sets of data. Differences among three or more groups were analyzed for statistical significance by one-way ANOVA followed by Bonferroni's multiple-comparison test. A $p$ value $<0.05$ was considered statistically significant. All tests were two-tailed. All data were expressed as mean \pm SEM.

\section{Results}

Most cortical GABAergic interneurons can be classified into the following four distinct classes based on the molecular markers: PV-positive cells, SST-positive cells, Reelin-positive/ SST-negative cells, and VIP-positive cells (Gelman and Marin, 2010). A majority of cortical GABAergic interneurons are either PV-positive cells or SST-positive cells and originate from the MGE (Xu et al., 2004; Fogarty et al., 2007). We first investigated which classes of neurons would differentiate from MGE cells transplanted into the neonatal PFC. MGE cells were dissected from E13.5 mouse embryos expressing GFP and grafted into the $\mathrm{mPFC}$ of neonatal wild-type recipient mice (Fig. $1 A$ ). One week after transplantation, many GFP-expressing cells were found dispersed from the injection site (Fig. $1 B$ ). Six weeks after transplantation, many GFP-expressing cells were found in the mPFC (Fig. $1 C, D)$, and our quantitative estimation revealed that the cells survived accounted for $\sim 25 \%$ of the cells injected $(2.5 \pm 0.2 \times$ $10^{4}$ cells in each hemisphere, $n=4$ hemispheres). Many of the GFP-expressing cells were positive for the neuronal marker NeuN $(90.0 \pm 3.0 \%, n=230$ GFP-expressing cells, 6 hemispheres) and GABA ( $65.7 \pm 4.0 \%, n=147$ GFP-expressing cells, 6 hemispheres). In contrast, no or only a few cells expressed the oligodendrocyte marker CNPase $(0.0 \pm 0.0 \%, n=119$ GFPexpressing cells, 6 hemispheres) or the astrocyte marker GFAP $(0.6 \pm 0.6 \%, n=221$ GFP-expressing cells, 6 hemispheres), suggesting that a majority of the transplanted cells had differentiated into GABAergic interneurons. Examination of the interneuron subtype markers revealed that many GFP-expressing cells were positive for SST and Reelin (Fig. $1 E, F$ ) but negative for PV and VIP (Fig. $1 F$ ) and that most GFP/Reelin-double-positive cells were also positive for SST (Fig. $1 E, F$ ). The density of the GFPexpressing cells (Fig. 1D) and their interneuron subtypes (Fig. $1 F$ ) were largely constant across the subregions within the mPFC. We also found that GFP-expressing cells accounted for 7\% (7.0 \pm $1.5 \%, n=1651$ GABA-positive cells, 6 hemispheres) of the total number of recipient GABA-positive cells within the $\mathrm{mPFC}$ and $11 \%(10.9 \pm 2.4 \%, n=611$ SST-positive cells, 6 hemispheres $)$ of the total number of recipient SST-positive cells within the mPFC. Thus, a majority of the transplanted MGE cells had differentiated into an SST/Reelin-expressing class of GABAergic interneurons and constituted a substantial number of the interneurons within the $\mathrm{mPFC}$ of the recipient mice.

The neurochemical differentiation into cortical GABAergic interneurons by the MGE cells that had been transplanted prompted us to investigate whether these cells would be functionally integrated into the PFC neuronal circuitry of the host. Since c-Fos, an immediate early gene product, is known to be expressed in animals in response to various physiological stimuli, including exposure to a novel enriched environment (Staiger et al., 2000; Carlén et al., 2002; Tashiro et al., 2006; Kee et al., 2007; Ohira et al., 2010), we next investigated c-Fos expression in transplanted cells within the $\mathrm{mPFC}$ in response to exposure to a novel enriched environment 6 weeks after transplantation (Fig. 2A). When mice were housed in their original cage, only a few GFPexpressing cells in the mPFC showed c-Fos immunoreactivity (Fig. 2B,E). However, $1 \mathrm{~h}$ after exposure to a novel enriched environment for $10 \mathrm{~min}$ (Fig. 2A), the percentage of GFPpositive cells that expressed $c$-Fos was significantly higher than in the controls (Fig. 2C-E). In view of the fact that most of the transplanted cells differentiated into GABAergic interneurons (Fig. 1), these results suggest that at least some of the transplanted GABAergic interneurons had become functionally integrated into the PFC neuronal circuitry of the host.

We then investigated whether transplantation prevented the PCP-induced cognitive deficits by measuring the cognitive function of mice with the NORT (Ennaceur and Delacour, 1988; Tang et al., 1999; Niwa et al., 2010). The mice were exposed to two objects during the training session, and $1 \mathrm{~d}$ later they were tested for their ability to discriminate between a familiar object and a novel object during a retention session in which one of the two objects used in the training session had been replaced by a novel object (see Materials and Methods). PCP or vehicle was administered $30 \mathrm{~min}$ before the training session (Fig. $3 A$ ). The results showed that PCP-treated mice that had not undergone cell transplantation exhibited impaired performance in exploratory preference during the retention sessions (Fig. $3 C$ ), but that the PCP-induced impairment was significantly prevented in the mice that had undergone prior MGE cell transplantation (Fig. $3 C)$. This preventive effect of MGE cell transplantation was not reproduced by transplantation of cells from E13.5 rostromedial cortex, which is the presumptive $\mathrm{mPFC}$ region and should mainly contain the excitatory projection neuron precursors/progenitors (Fig. 3C). Indeed, at 6 weeks after transplantation the rostromedial cortex cells that had been transplanted into the neonatal mPFC expressed the callosal projection neuron markers Satb2 (72.6 $\pm 6.7 \%, n=491$ GFP-expressing cells, 5 hemispheres) and the subcortical projection neuron marker Ctip2 (33.0 $\pm 4.2 \%$, $n=521$ GFP-expressing cells, 5 hemispheres), suggesting that most of them had differentiated into cortical projection neurons. Thus, the preventive effect of MGE cell transplantation against the impaired performance in exploratory preference (Fig. $3 C$ ) was not due to a nonspecific effect of transplantation of any neuronal precursors. There were no significant differences in exploratory time between the groups that showed significant differences in performance in the exploratory preference (Fig. $3 C, D$ ), suggesting that the differences in the performance in exploratory preference (Fig. 3C) were not due to the differences between the groups in curiosity and/or motivation to explore objects. MGE 
A
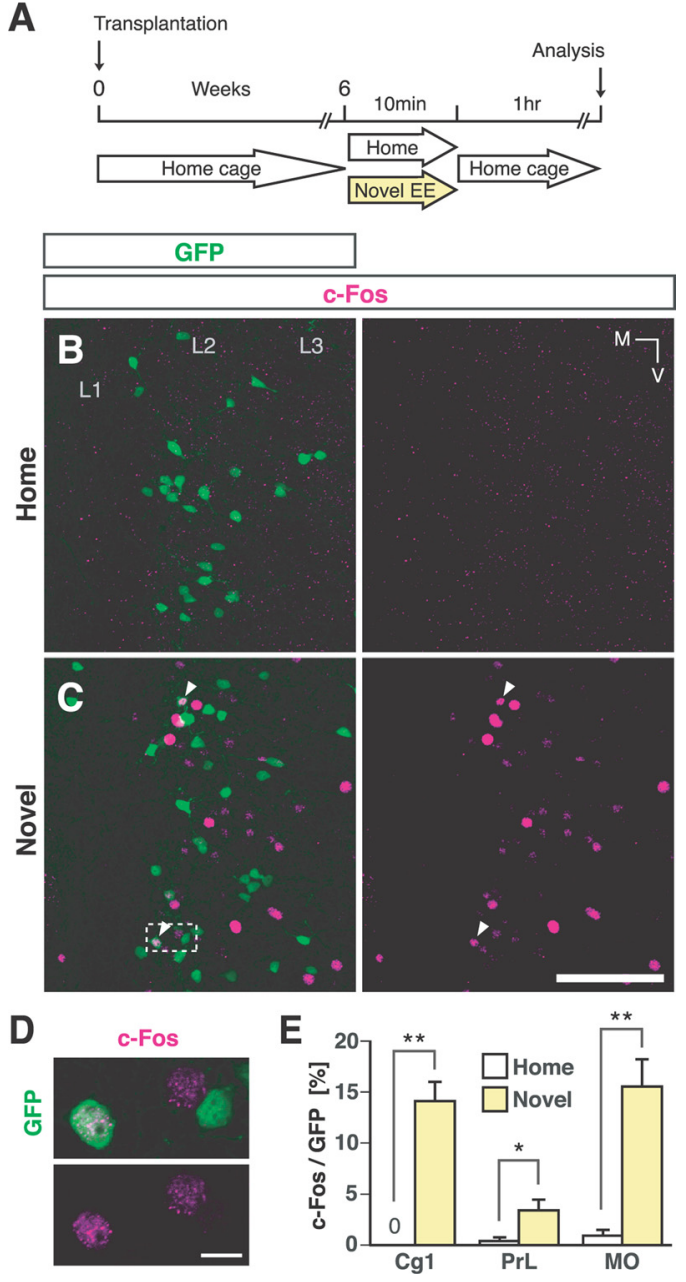

Figure 2. Some transplanted MGE cells were functionally integrated into the host neuronal circuitry within the $\mathrm{MPFC}$. $A$, Schema of the experimental design for investigating the functional integration of the transplanted cells into the neuronal circuitry of the host. Both the control mice and experimental mice underwent MGE cell transplantation. The experimental mice were exposed to a novel enriched environment for 10 min at 6 weeks after transplantation (yellow arrow), then returned to their home cages, and their brains were analyzed $1 \mathrm{~h}$ later. Control mice continued to be housed in their home cages. $\boldsymbol{B}, \boldsymbol{C}$, Expression of $\mathrm{C}-\mathrm{Fos}$ (magenta) in GFPexpressing cells (green) within the PrL in the control mice $(\boldsymbol{B})$ and mice exposed to a novel enriched environment (C). Some GFP-expressing cells in the mice exposed to a novel enriched environment expressed c-Fos (arrowheads). D, Enlarged single-optical-sectional view of the boxed region in $\boldsymbol{C}$. $\boldsymbol{E}$, The percentages of GFP-expressing cells that expressed c-Fos within the $\mathrm{Cg} 1$ ( $n=345$ GFP-expressing cells), the PrL ( $n=522$ GFP-expressing cells), and the M0 ( $n=$ 500 GFP-expressing cells) of the control mice (white bars) ( $n=6$ hemispheres) and within the Cg1 ( $n=733$ GFP-expressing cells), the PrL ( $n=962$ GFP-expressing cells), and the M0 ( $n=$ 1088 GFP-expressing cells) of mice exposed to a novel enriched environment (yellow bars) ( $n=$ 8 hemispheres). ${ }^{* *} p=0.0007 ;{ }^{*} p=0.042$ (Mann-Whitney Utest). EE, Enriched environment; L1-3, layers 1-3; M, medial; V, ventral. Scale bars: $\boldsymbol{B}, \mathbf{C}, 200 \mu \mathrm{m} ; \boldsymbol{D}, 10 \mu \mathrm{m}$.

cell transplantation alone did not enhance performance in exploratory preference or exploratory time (Fig. 3C,D). Thus, MGE cell transplantation into the mPFC had preventive effects against induction of the cognitive deficits by PCP.

To investigate whether this preventive effect could be obtained by MGE cell transplantation into other cortical regions, we then transplanted MGE cells into the neonatal occipital cortex, the presumptive region of the primary visual cortex (Fig. 3B). Similar to the results of transplantation into the MPFC (Fig. 1), a majority of the transplanted cells expressed GABA $(64.1 \pm 3.1 \%$, $n=328$ GFP-expressing cells, 6 hemispheres) at 6 weeks after transplantation, suggesting that most of them had differentiated into cortical GABAergic interneurons. Interestingly, however, the interneuron subtypes of the cells transplanted into the occipital cortex were significantly different from the subtypes after transplantation into the mPFC (Fig. 1): more transplanted cells expressed PV (50.6 $\pm 3.6 \%, n=291$ GFP-expressing cells, 6 hemispheres; $p=0.0043$ ) compared with the cells in the MO after transplantation into the mPFC [11.2 $\pm 4.9 \%$ (Fig. $1 F$ ), MannWhitney $U$ test] and fewer transplanted cells expressed SST (37.1 $\pm 3.2 \%, n=328$ GFP-expressing cells, 6 hemispheres; $p=$ 0.0022) compared with the cells in the MO after transplantation into the mPFC $[64.1 \pm 4.3 \%$ (Fig. $1 F$ ), Mann-Whitney $U$ test]. Even though the grafted cells had differentiated into GABAergic interneurons, MGE cell transplantation into the occipital cortex had no significant effect on the induction of the cognitive deficits by PCP (Fig. $3 E, F$ ). Thus, the preventive effect of MGE cell transplantation into the mPFC on PCP-induced cognitive deficits (Fig. $3 C, D$ ) was not a nonspecific effect of MGE cell transplantation into any cortical regions.

The finding that MGE cell transplantation into the mPFC significantly prevented impairment of a cortex-dependent task (Fig. $3 C, D$ ) raised the possibility that it might also prevent the impairment of other cortex-dependent functions that are known to be impaired by PCP administration. We therefore measured PPI, which reflects the sensory-motor gating function, a major indicator of information processing involving the cortex that is frequently impaired in schizophrenia (Arguello and Gogos, 2006). The results showed that PCP-treated mice that had not undergone cell transplantation displayed decreased PPI (Fig. $3 G, I$ ), but that the PCP-induced decrease was significantly prevented in mice that had undergone MGE cell transplantation into the mPFC (Fig. 3G). This preventive effect of MGE cell transplantation was not reproduced by either transplantation of rostromedial cortex cells into the mPFC (Fig. 3G) or of MGE cells into the occipital cortex (Fig. 3I). No statistically significant differences were observed in acoustic startle amplitude among any of the conditions (Fig. $3 \mathrm{H}, \mathrm{J}$ ), and MGE cell transplantation into the mPFC alone did not enhance PPI or the acoustic startle response (Fig. 3G,H). Thus, MGE cell transplantation into the mPFC had a preventive effect on the PCP-induced sensory-motor gating deficit.

The significant preventive effects of MGE cell transplantation into the MPFC on PCP-induced behavioral deficits raised the possibility that transplantation of the cells had altered mPFC activity in response to PCP. We focused on the preventive effect on PCP-induced cognitive deficits detected by NORT and on mPFC activity during NORT. Since NMDA receptor antagonists impair the encoding of recognition memory in mice, but not their memory consolidation and retrieval processes, and the encoding process should occur during the training session in the NORT (Nilsson et al., 2007), we then focused on mPFC activity during the training session in the NORT. To evaluate mPFC activity during the training session, brains were fixed $1 \mathrm{~h}$ after the training session (Fig. 4A), and the mPFC was analyzed for c-Fos expression. The results showed that the numbers of c-Fospositive cells within both the PrL and the MO were significantly higher in the PCP-treated mice that had undergone MGE cell transplantation than in the PCP-treated mice that had not undergone MGE cell transplantation (Fig. 4B-F). Most of the c-Fospositive cells in both of these regions were positive for Satb2, a marker of callosal projection neurons (Alcamo et al., 2008; Britanova et al., 2008) (Fig. 4G,H). These results suggested that prior MGE cell transplantation into the mPFC modulates the activity 
A

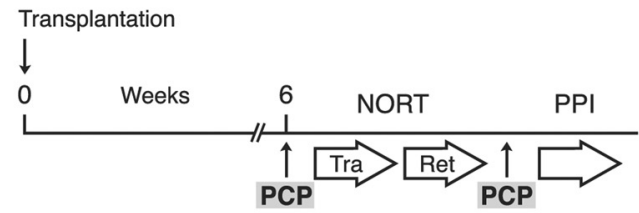

B

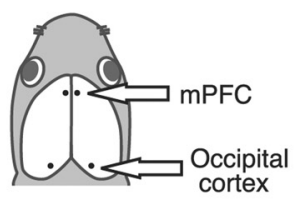

$\mid$
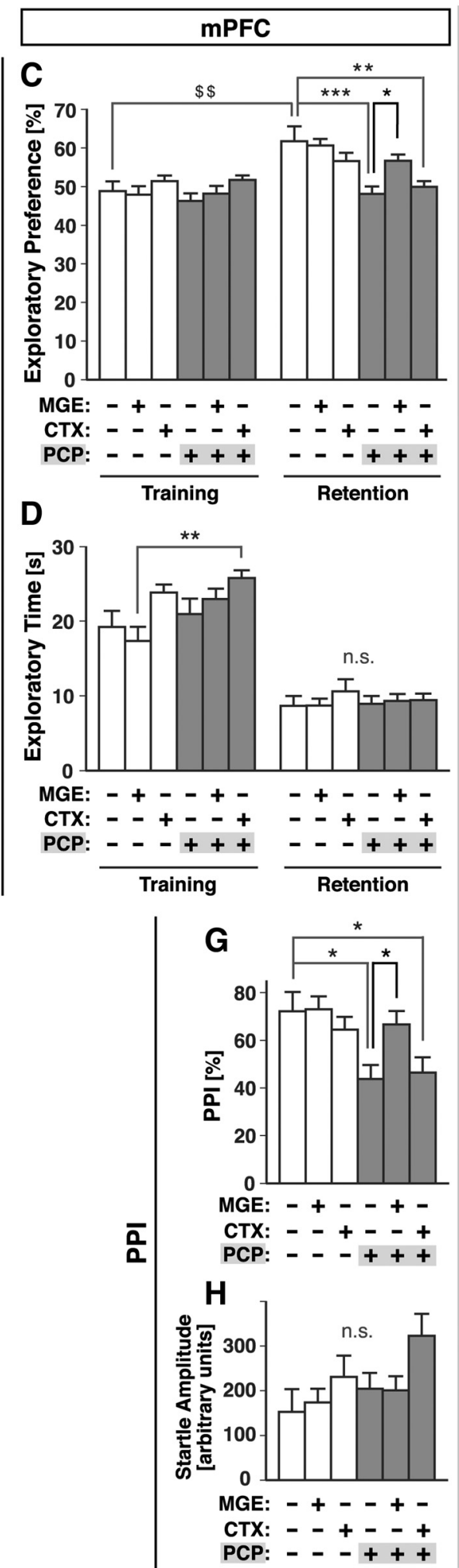

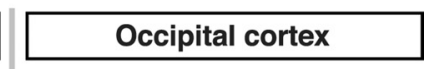

E

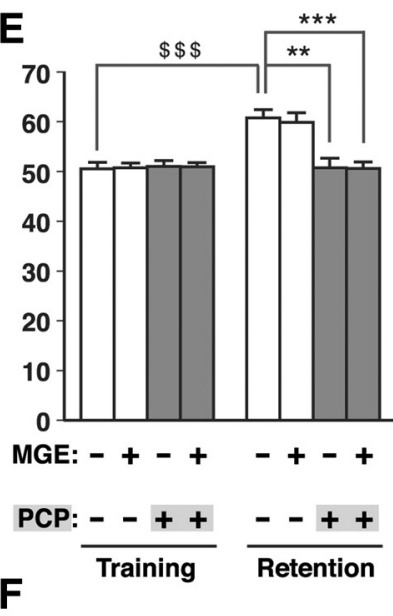

30

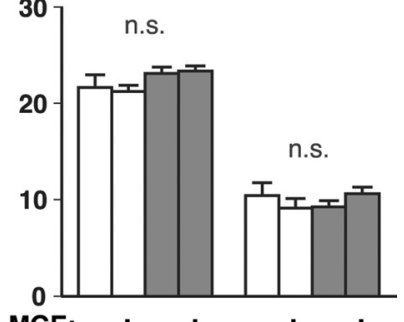

MGE: $-+-+\quad+-+$
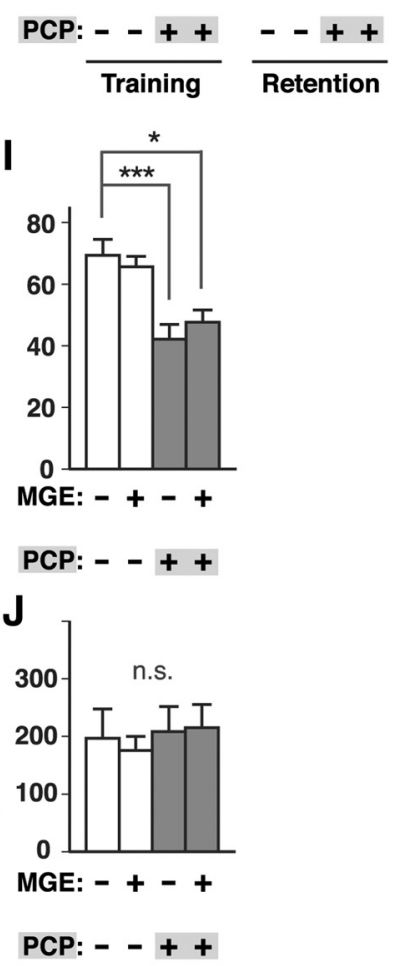

of callosal projection neurons in the $\mathrm{mPFC}$ in response to PCP during the training session in the NORT.

\section{Discussion}

Different interneuron subtypes in different cortical regions

Approximately $10 \%$ and $60 \%$ of the MGE cells transplanted into the mPFC differentiated into PV-positive interneurons and SST-positive interneurons, respectively (Fig. 1), as opposed to $\sim 50 \%$ and $35 \%$, respectively, when transplanted into the occipital cortex. Previous studies have shown that the fate of distinct classes of GABAergic interneurons is already largely determined in their progenitor cells in the subpallium (Gelman and Marin, 2010). Thus, the differences in interneuron subtypes between the mPFC and the occipital cortex may have been caused by the differences in the survival and/or differentiation of interneuron subtypes after transplantation, which reflects the differences between the environments in different cortical regions of the host. Identification of environmental factors that affect the final interneuron subtypes may enable us to control the number of a specific interneuron subtype and modulate a specific neuronal circuitry of the host after MGE cell transplantation in the future.

MGE cell transplantation did not cause behavioral effects in naive mice

Transplantation of MGE cells into the mPFC modified the response to PCP treatment, but did not cause significant behavioral effects in naive mice (Fig. 3). Thus, MGE cell transplantation into the $\mathrm{mPFC}$ has a certain degree of specificity in its effect on the response to PCP treatment. Although as stated above, there were differences in the tendency of the

$\leftarrow$

vehicle were transplanted into the $\operatorname{mPF}(\boldsymbol{B}, \boldsymbol{C}, \boldsymbol{F}, \boldsymbol{G})$ or occipital cortex $(\boldsymbol{D}, \boldsymbol{E}, \boldsymbol{H}, \boldsymbol{I})$ of $\mathrm{PO}$ neonates. PCP or vehicle was injected subcutaneously 6 weeks after transplantation, 30 min before each behavioral analysis. $\boldsymbol{B}$, Schema of bilateral transplantation into the $\mathrm{mPFC}$ or the occipital cortex of $\mathrm{PO}$ wild-type recipient mice (dots). Dorsal view of a head. Exploratory preference $(\boldsymbol{C}, \boldsymbol{E})$ and exploratory time $(\boldsymbol{D}, \boldsymbol{F})$ in the NORT during the training and retention sessions. PPI with an $86 \mathrm{~dB}$ prepulse $(\boldsymbol{G}, \boldsymbol{I})$ and acoustic startle amplitude $(\boldsymbol{H}, \boldsymbol{J})$ in the PPI test. Gray bars indicate the results obtained under $\mathrm{PCP}$-treated conditions. MGE-/CTX-/PCP- $(-/-/-)$ group, $n=14 ;+/-/-$ group, $n=14 ;-1+1-$ group, $n=11 ;-1-1+$ group, $n=13$; $+/-/+$ group, $n=17$; and $-/+/+$ group, $n=12$ in $C, D$, G, H. MGE-/PCP- $(-/-)$ group, $n=10 ;+/-$ group, $n=$ $15 ;-/+$ group, $n=14$; and $+/+$ group, $n=19$ in $\boldsymbol{E}, \boldsymbol{F}, \boldsymbol{I}$, J. ${ }^{\$ \$ \$} p<0.001 ;{ }^{\$ \$} p<0.01$ (paired $t$ test); ${ }^{* * *} p<0.001$; ${ }^{* *} p<0.01 ;{ }^{*} p<0.05$ (Bonferroni's test). Tra, Training; Ret, retention; (TX, cortex; n.S., not significant.

Figure 3. MGE cell transplantation into the MPFC prevented the induction of cognitive and sensory-motor gating deficits by PCP. $A$, Schema of the experimental design for behavioral analysis of the recipient mice. MGE cells, rostromedial cortex cells, or 
A
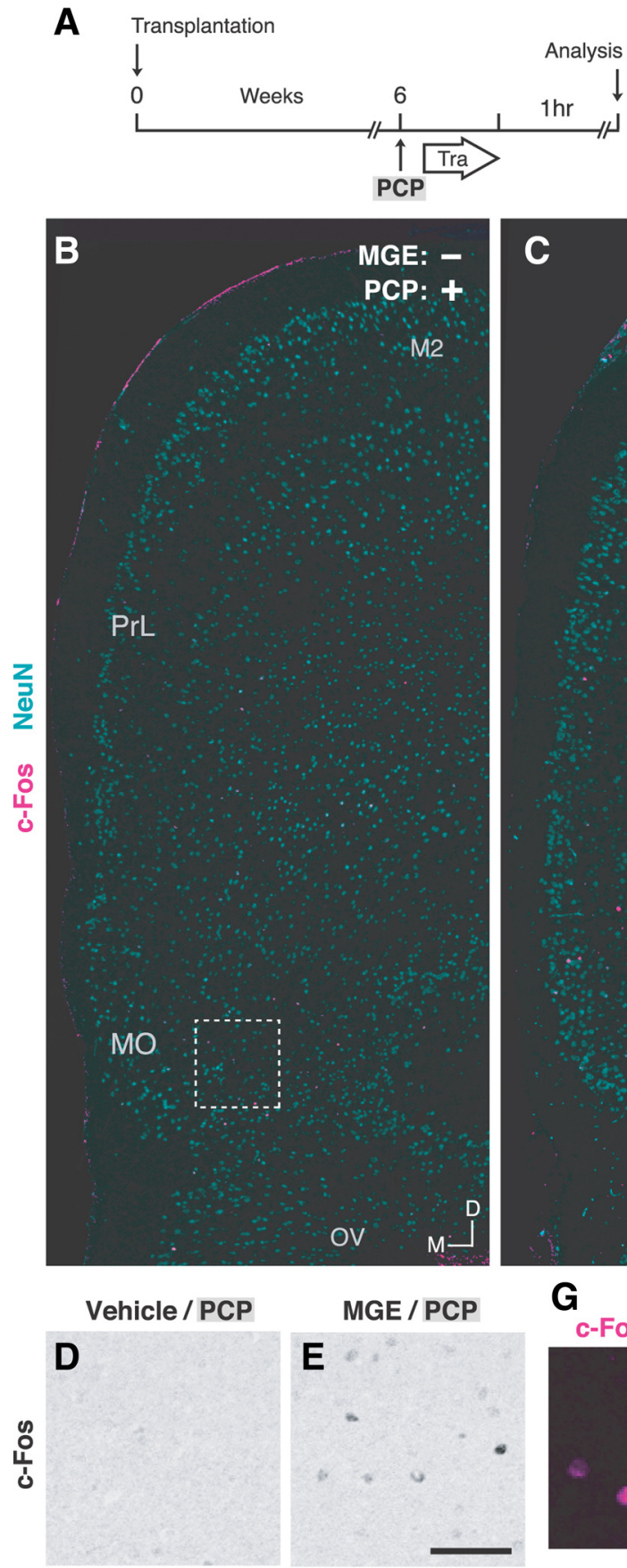

$\mathbf{F}$

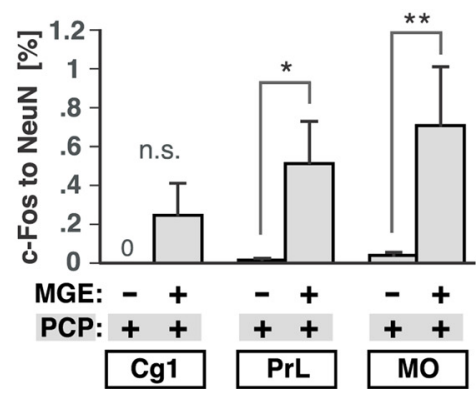

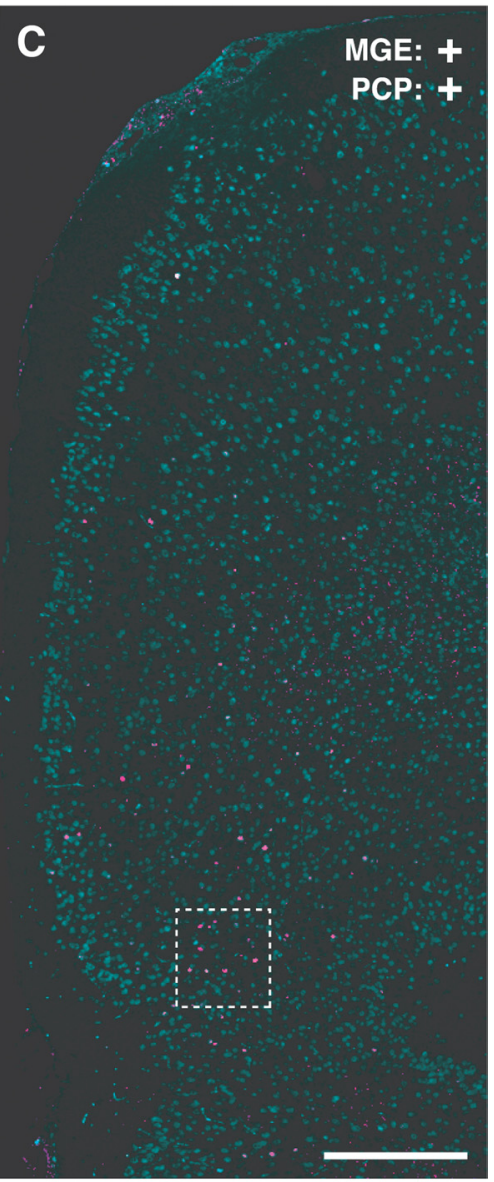

G

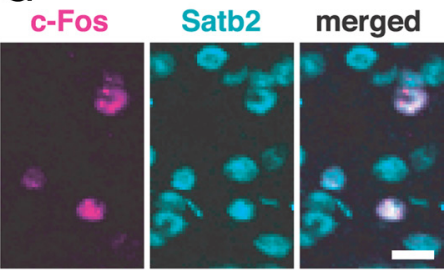

H

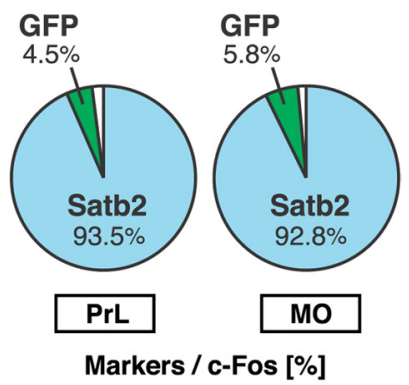

Figure 4. Prior MGE cell transplantation into the mPFC increased the activity of callosal projection neurons in the mPFC in response to the PCP. A, Schema of the experimental design to investigate neuronal activity during the training session in the NORT. The design was the same as that used for the behavioral analysis (Fig. $3 A$ ), but brains were analyzed $1 \mathrm{~h}$ after the training session in the NORT. $\boldsymbol{B}, \boldsymbol{C}, \mathrm{C}-\mathrm{F}$ os expression (magenta) within the MPFC in mice injected with vehicle at PO and with PCP at 6 weeks (MGE $-/ P C P+$ group) $(B)$ and in mice that underwent MGE cell transplantation at $P 0$ and were injected with $P C P$ at 6 weeks

transplanted cells to survive and/or differentiate into certain interneuron subtypes according to the cortical areas into which they had been transplanted, the transplanted MGE cells were highly motile, dispersed widely, and intermingled with the endogenous neurons in both neonatal and adult brain (Wichterle et al., 1999; Alvarez-Dolado et al., 2006; MartínezCerdeño et al., 2010; Southwell et al., 2010; present study). We hypothesize that the cortical neuronal network is largely permissive for functional integration of transplanted MGE cells, and that the basal excitation/inhibition ratio in the PFC can be readjusted to prevent behavioral abnormalities in the host. This readjustment may be accompanied by structural alterations of the neuronal circuit (Southwell et al., 2010) in the PFC, and that may modify the behavioral response to PCP treatment. We cannot rule out the possibility, however, that MGE cell transplantation into the $\mathrm{mPFC}$ may also have behavioral effects on naive mice (Martínez-Cerdeño et al., 2010) that were not detected in the present study.

\section{Mechanisms by which MGE cell transplantation increased the c-Fos level in the PrL and the MO}

MGE cell transplantation into the neonatal mPFC significantly increased the activity of callosal projection neurons within the PrL and the MO in response to PCP (Fig. 4). The mechanism responsible for the absence of a significant increase in activity in the Cg1 alone (Fig. $4 F$ ) remains unclear. The properties of the transplanted MGE cells in the different subregions of the $\mathrm{mPFC}$ were indistinguishable

$\leftarrow$

(MGE $+/ P C P+$ group) (C). D, E, c-Fos expression (black) in enlarged views of the boxed regions in $\boldsymbol{B}$ and $\boldsymbol{C}$, respectively. $\boldsymbol{F}$, Ratio of the number of c-Fos-positive cells to the number of NeuN-positive cells within the Cg1 ( $n=0$ c-Fos-positive cell, 5951 NeuN-positive cells), the PrL ( $n=2$ c-Fos-positive cells, 15,904 NeuN-positive cells), and the MO ( $n=13$ c-Fospositive cells, 34,047 NeuN-positive cells) in the MGE-/ $\mathrm{PCP}+$ group $(n=12$ hemispheres) and within the $\mathrm{Cg} 1$ ( $n=$ 13 c-Fos-positive cells, 6373 NeuN-positive cells), the PrL ( $n=$ 88 c-Fos-positive cells, 17,520 NeuN-positive cells), and the M0 ( $n=226$ c-Fos-positive cells, 35,591 NeuN-positive cells) in the MGE $+/ P C P+$ group ( $n=12$ hemispheres). ${ }^{* *} p=$ $0.0023 ;{ }^{*} p=0.0387$ (Mann-Whitney U test). G, Expression of Satb2 (light blue) in c-Fos-positive cells (magenta) in the M0 in the MGE + $/ P C P+$ mouse. $\boldsymbol{H}$, Calculation of the percentage of c-Fos-positive cells expressing Satb2 and GFP within the PrL ( $n=153$ c-Fos-positive cells) and the M0 ( $n=277$ c-Fospositive cells) in the MGE $+/ P C P+$ group ( $n=6$ hemispheres). Tra, training; $M 2$, secondary motor cortex; $O V$, olfactory ventricle; $M$, medial; $D$, dorsal. Scale bars: $B, C, 500$ $\mu \mathrm{m} ; \boldsymbol{D}, \boldsymbol{E}, 100 \mu \mathrm{m} ; \boldsymbol{G}, 20 \mu \mathrm{m}$. 
in terms of cell density (Fig. $1 D$ ), interneuron subtypes (Fig. $1 F$ ), and functional integration (Fig. 2E), suggesting that differences between the transplanted cells according to the subregions of the mPFC may not explain the mechanism.

Another interesting question in regard to mechanisms is how the increase in callosal projection neuron activity in the mPFC was induced by MGE cell transplantation. Since previous studies have shown that systemic administration of NMDA receptor antagonists disinhibits projection neurons in the PFC by decreasing the activity of GABAergic interneurons (Homayoun and Moghaddam, 2007) and that MGE cell transplantation increases GABA-mediated inhibition on host projection neurons and modulates host neuronal circuitry and its activity (AlvarezDolado et al., 2006; Baraban et al., 2009; Southwell et al., 2010; Zipancic et al., 2010), one might expect MGE cell transplantation to increase the level of inhibition on host projection neurons and decrease the amount of disinhibition produced by PCP, thereby diminishing c-Fos level relative to level observed in the absence of MGE cell transplantation. In reality, however, MGE cell transplantation increased the c-Fos level in host mPFC callosal projection neurons relative to its level in the absence of MGE cell transplantation (Fig. 4). One possible explanation for this unexpected result is that, rather than contributing to general suppression of the activities of callosal projection neurons, the transplanted MGE cells had contributed to generation of their rhythmic activity. This may then facilitate signal transduction of callosal projection neurons and efficiently activate their target cells, including homotopic callosal projection neurons in the contralateral hemisphere (Audinat et al., 1988; Cassell et al., 1989; Kuroda et al., 1995; Reep et al., 1996; Carr and Sesack, 1998), which, in turn, may ultimately lead to activation of the reciprocal network between homotopic callosal projection neurons across hemispheres and expression of c-Fos in Satb2-positive cells within the mPFC (Fig. 4). In support of this hypothesis, most MGE cells transplanted into the neonatal mPFC differentiate into a SST-expressing class of interneurons (Fig. 1) that may be involved in cortical rhythmogenesis (Gibson et al., 1999, 2005; Beierlein et al., 2000). Interestingly, most transplanted SSTexpressing interneurons expressed Reelin (Fig. 1), which enhances signal transduction through NMDA receptors (Herz and Chen, 2006; Knuesel, 2010). The Reelin secreted by the transplanted cells may enhance the NMDA receptor function of surrounding cells, including the function of the endogenous GABAergic interneurons of the host. Thus, transplanted SSTpositive cells and/or other GABAergic interneurons whose NMDA receptor-mediated signaling has been upregulated by Reelin might increase the rhythmic activity of callosal projection neurons. Since c-Fos expression appears to reflect the activity level but not the activity pattern of neurons, direct measurement of the activity pattern of callosal projection neurons, by electrophysiological recordings, for example, may be required to assess their rhythmic activity. A previous study has shown that the activity of SST-positive cells appears to be blocked by NMDA receptor antagonists more easily than the activity of PV-positive interneurons (Lu et al., 2007). The above-described possible effect of Reelin on surrounding cells may explain how transplanted SST-positive interneurons could change mPFC activity even in the presence of PCP. It will be important to determine whether the Reelin secreted by transplanted MGE cells is involved in the effect of the MGE cell transplantation by transplanting MGE cells derived from the Reelin-deficient reeler mutants (D'Arcangelo et al., 1995).

\section{Mechanisms by which MGE cell transplantation prevents PCP-induced behavioral deficits}

It remains unclear how MGE cell transplantation prevented PCPinduced behavioral deficits. Although we found that the preventive effect of MGE cell transplantation on the PCP-induced behavioral deficits was accompanied by an increase in the c-Fos level in the mPFC (Fig. 4), it remains unclear whether the increases of c-Fos levels in the MPFC are causally related to the effects of MGE cell transplantation on the behavioral deficits induced by PCP. The next intriguing question, therefore, is whether the activation of the callosal projection neurons within the PrL and the $\mathrm{MO}$ is required and/or sufficient to produce significant behavioral effects of MGE cell transplantation. It might be possible to answer this question by specifically inactivating and/or activating Satb2-postive cells within the PrL and the MO, for example, by means of an optogenetic technique (Zhang et al., 2007).

One might argue that the mechanisms by which MGE cell transplantation prevents PCP-induced behavioral effects are unlikely to be related to modulating the alterations in PFC excitatory/inhibitory balance that are usually produced by PCP. In support of this argument, in contrast to a previous study (Kargieman et al., 2007), c-Fos expression was rarely detected after PCP administration alone in the present study (Fig. 4). Furthermore, as mentioned above, MGE cell transplantation increased, not decreased, the c-Fos level in the mPFC (Fig. 4). How, then, might MGE cell transplantation prevent PCP-induced behavioral effects? One possible explanation is that rather than simply augmenting the strength of the endogenous, mature inhibitory connections, the transplanted MGE cells might reorganize the PFC circuitry by introducing a new set of weak, but numerous, inhibitory synapses on host projection neurons (Southwell et al., 2010). Such a structural and functional reorganization of the PFC as a result of the transplantation may increase tolerance to PCP and thereby lead to the prevention of PCP-induced behavioral deficits.

\section{Alternative means of increasing the number of interneuron precursors in the $\mathrm{mPFC}$}

Although we transplanted embryonic MGE cells to increase the number of interneuron precursors in the neonatal mPFC, an increase could be achieved by other means as well. For example, prospective MGE cells generated by pluripotent stem cells in vitro (Maroof et al., 2010; Danjo et al., 2011) could be used as graft cells. Manipulation of endogenous cells might also be possible, including by proliferative activation of interneuron progenitors present even in the adult cortex (Ohira et al., 2010) and directing postmitotic migrating interneurons to the PFC by, for example, injecting their in vivo attractant CXCL12 (Li et al., 2008; Tanaka et al., 2009) into the mPFC.

\section{Clinical implications}

The cognitive symptoms of schizophrenia are largely resistant to current pharmacological treatments and preventive approaches to their development have not been adequately explored (Keefe et al., 2007). Our findings in this study may contribute to the development of a cell-based approach as a novel means of preventing and possibly of treating the schizophreniform cognitive deficits.

\section{References}

Alcamo EA, Chirivella L, Dautzenberg M, Dobreva G, Fariñas I, Grosschedl R, McConnell SK (2008) Satb2 regulates callosal projection neuron identity in the developing cerebral cortex. Neuron 57:364-377. 
Alvarez-Dolado M, Calcagnotto ME, Karkar KM, Southwell DG, Jones-Davis DM, Estrada RC, Rubenstein JL, Alvarez-Buylla A, Baraban SC (2006) Cortical inhibition modified by embryonic neural precursors grafted into the postnatal brain. J Neurosci 26:7380-7389.

Arguello PA, Gogos JA (2006) Modeling madness in mice: one piece at a time. Neuron 52:179-196.

Audinat E, Condé F, Crépel F (1988) Cortico-cortical connections of the limbic cortex of the rat. Exp Brain Res 69:439-443.

Baraban SC, Southwell DG, Estrada RC, Jones DL, Sebe JY, Alfaro-Cervello C, García-Verdugo JM, Rubenstein JL, Alvarez-Buylla A (2009) Reduction of seizures by transplantation of cortical GABAergic interneuron precursors into Kv1.1 mutant mice. Proc Natl Acad Sci U S A 106:15472-15477.

Beierlein M, Gibson JR, Connors BW (2000) A network of electrically coupled interneurons drives synchronized inhibition in neocortex. Nat Neurosci 3:904-910.

Britanova O, de Juan Romero C, Cheung A, Kwan KY, Schwark M, Gyorgy A, Vogel T, Akopov S, Mitkovski M, Agoston D, Sestan N, Molnár Z, Tarabykin V (2008) Satb2 is a postmitotic determinant for upper-layer neuron specification in the neocortex. Neuron 57:378-392.

Cardin JA, Carlén M, Meletis K, Knoblich U, Zhang F, Deisseroth K, Tsai LH, Moore CI (2009) Driving fast-spiking cells induces gamma rhythm and controls sensory responses. Nature 459:663-667.

Carlén M, Cassidy RM, Brismar H, Smith GA, Enquist LW, Frisén J (2002) Functional integration of adult-born neurons. Curr Biol 12:606-608.

Carr DB, Sesack SR (1998) Callosal terminals in the rat prefrontal cortex: synaptic targets and association with GABA-immunoreactive structures. Synapse 29:193-205.

Cassell MD, Chittick CA, Siegel MA, Wright DJ (1989) Collateralization of the amygdaloid projections of the rat prelimbic and infralimbic cortices. J Comp Neurol 279:235-248.

Danjo T, Eiraku M, Muguruma K, Watanabe K, Kawada M, Yanagawa Y, Rubenstein JL, Sasai Y (2011) Subregional specification of embryonic stem cell-derived ventral telencephalic tissues by timed and combinatory treatment with extrinsic signals. J Neurosci 31:1919-1933.

D’Arcangelo G, Miao GG, Chen SC, Soares HD, Morgan JI, Curran T (1995) A protein related to extracellular matrix proteins deleted in the mouse mutant reeler. Nature 374:719-723.

Ennaceur A, Delacour J (1988) A new one-trial test for neurobiological studies of memory in rats. 1: Behavioral data. Behav Brain Res 31:47-59.

Fogarty M, Grist M, Gelman D, Marín O, Pachnis V, Kessaris N (2007) Spatial genetic patterning of the embryonic neuroepithelium generates GABAergic interneuron diversity in the adult cortex. J Neurosci 27:10935-10946.

Franklin KBJ, Paxinos G (2008) The mouse brain in stereotaxic coordinates, Ed 3. New York: Academic.

Fuchs EC, Zivkovic AR, Cunningham MO, Middleton S, Lebeau FE, Bannerman DM, Rozov A, Whittington MA, Traub RD, Rawlins JN, Monyer H (2007) Recruitment of parvalbumin-positive interneurons determines hippocampal function and associated behavior. Neuron 53:591-604.

Gelman DM, Marín O (2010) Generation of interneuron diversity in the mouse cerebral cortex. Eur J Neurosci 31:2136-2141.

Gibson JR, Beierlein M, Connors BW (1999) Two networks of electrically coupled inhibitory neurons in neocortex. Nature 402:75-79.

Gibson JR, Beierlein M, Connors BW (2005) Functional properties of electrical synapses between inhibitory interneurons of neocortical layer 4 . J Neurophysiol 93:467-480.

Herz J, Chen Y (2006) Reelin, lipoprotein receptors and synaptic plasticity. Nat Rev Neurosci 7:850-859.

Homayoun H, Moghaddam B (2007) NMDA receptor hypofunction produces opposite effects on prefrontal cortex interneurons and pyramidal neurons. J Neurosci 27:11496-11500.

Jackson ME, Homayoun H, Moghaddam B (2004) NMDA receptor hypofunction produces concomitant firing rate potentiation and burst activity reduction in the prefrontal cortex. Proc Natl Acad Sci U S A 101:8467-8472.

Javitt DC, Zukin SR (1991) Recent advances in the phencyclidine model of schizophrenia. Am J Psychiatry 148:1301-1308.

Kargieman L, Santana N, Mengod G, Celada P, Artigas F (2007) Antipsychotic drugs reverse the disruption in prefrontal cortex function produced by NMDA receptor blockade with phencyclidine. Proc Natl Acad Sci U S A 104:14843-14848.
Kawaguchi Y, Kubota Y (1997) GABAergic cell subtypes and their synaptic connections in rat frontal cortex. Cereb Cortex 7:476-486.

Kee N, Teixeira CM, Wang AH, Frankland PW (2007) Preferential incorporation of adult-generated granule cells into spatial memory networks in the dentate gyrus. Nat Neurosci 10:355-362.

Keefe RS, Bilder RM, Davis SM, Harvey PD, Palmer BW, Gold JM, Meltzer HY, Green MF, Capuano G, Stroup TS, McEvoy JP, Swartz MS, Rosenheck RA, Perkins DO, Davis CE, Hsiao JK, Lieberman JA (2007) Neurocognitive effects of antipsychotic medications in patients with chronic schizophrenia in the CATIE Trial. Arch Gen Psychiatry 64:633-647.

Kiss T, Hoffmann WE, Hajós M (2011) Delta oscillation and short-term plasticity in the rat medial prefrontal cortex: modelling NMDA hypofunction of schizophrenia. Int J Neuropsychopharmacol 14:29-42.

Klausberger T, Marton LF, O’Neill J, Huck JH, Dalezios Y, Fuentealba P, Suen WY, Papp E, Kaneko T, Watanabe M, Csicsvari J, Somogyi P (2005) Complementary roles of cholecystokinin- and parvalbumin-expressing GABAergic neurons in hippocampal network oscillations. J Neurosci 25:9782-9793.

Knuesel I (2010) Reelin-mediated signaling in neuropsychiatric and neurodegenerative diseases. Prog Neurobiol 91:257-274.

Korotkova T, Fuchs EC, Ponomarenko A, von Engelhardt J, Monyer H (2010) NMDA receptor ablation on parvalbumin-positive interneurons impairs hippocampal synchrony, spatial representations, and working memory. Neuron 68:557-569.

Kuroda M, Murakami K, Shinkai M, Ojima H, Kishi K (1995) Electron microscopic evidence that axon terminals from the mediodorsal thalamic nucleus make direct synaptic contacts with callosal cells in the prelimbic cortex of the rat. Brain Res 677:348-353.

Lavdas AA, Grigoriou M, Pachnis V, Parnavelas JG (1999) The medial ganglionic eminence gives rise to a population of early neurons in the developing cerebral cortex. J Neurosci 19:7881-7888.

Li G, Adesnik H, Li J, Long J, Nicoll RA, Rubenstein JL, Pleasure SJ (2008) Regional distribution of cortical interneurons and development of inhibitory tone are regulated by Cxcl12/Cxcr4 signaling. J Neurosci 28:1085-1098.

Lu JT, Li CY, Zhao JP, Poo MM, Zhang XH (2007) Spike-timing-dependent plasticity of neocortical excitatory synapses on inhibitory interneurons depends on target cell type. J Neurosci 27:9711-9720.

Maddox VH, Godefroi EF, Parcell RF (1965) The synthesis of phencyclidine and other 1-arylcyclohexylamines. J Med Chem 8:230-235.

Maroof AM, Brown K, Shi SH, Studer L, Anderson SA (2010) Prospective isolation of cortical interneuron precursors from mouse embryonic stem cells. J Neurosci 30:4667-4675.

Martínez-Cerdeño V, Noctor SC, Espinosa A, Ariza J, Parker P, Orasji S, Daadi MM, Bankiewicz K, Alvarez-Buylla A, Kriegstein AR (2010) Embryonic MGE precursor cells grafted into adult rat striatum integrate and ameliorate motor symptoms in 6-OHDA-lesioned rats. Cell Stem Cell 6:238-250

Miyoshi G, Hjerling-Leffler J, Karayannis T, Sousa VH, Butt SJ, Battiste J, Johnson JE, Machold RP, Fishell G (2010) Genetic fate mapping reveals that the caudal ganglionic eminence produces a large and diverse population of superficial cortical interneurons. J Neurosci 30:1582-1594.

Modo M, Stroemer RP, Tang E, Patel S, Hodges H (2003) Effects of implantation site of dead stem cells in rats with stroke damage. Neuroreport 14:39-42.

Mouri A, Noda Y, Enomoto T, Nabeshima T (2007a) Phencyclidine animal models of schizophrenia: approaches from abnormality of glutamatergic neurotransmission and neurodevelopment. Neurochem Int 51:173-184.

Mouri A, Noda Y, Hara H, Mizoguchi H, Tabira T, Nabeshima T (2007b) Oral vaccination with a viral vector containing Abeta cDNA attenuates age-related Abeta accumulation and memory deficits without causing inflammation in a mouse Alzheimer model. FASEB J 21:2135-2148.

Nilsson M, Hansson S, Carlsson A, Carlsson ML (2007) Differential effects of the $N$-methyl-D-aspartate receptor antagonist MK-801 on different stages of object recognition memory in mice. Neuroscience 149:123-130.

Niwa M, Kamiya A, Murai R, Kubo K, Gruber AJ, Tomita K, Lu L, Tomisato S, Jaaro-Peled H, Seshadri S, Hiyama H, Huang B, Kohda K, Noda Y, O’Donnell P, Nakajima K, Sawa A, Nabeshima T (2010) Knockdown of DISC1 by in utero gene transfer disturbs postnatal dopaminergic maturation in the frontal cortex and leads to adult behavioral deficits. Neuron 65:480-489.

Ohira K, Furuta T, Hioki H, Nakamura KC, Kuramoto E, Tanaka Y, Funatsu 
N, Shimizu K, Oishi T, Hayashi M, Miyakawa T, Kaneko T, Nakamura S (2010) Ischemia-induced neurogenesis of neocortical layer 1 progenitor cells. Nat Neurosci 13:173-179.

Okabe M, Ikawa M, Kominami K, Nakanishi T, Nishimune Y (1997) 'Green mice' as a source of ubiquitous green cells. FEBS Lett 407:313-319.

Reep RL, Corwin JV, King V (1996) Neuronal connections of orbital cortex in rats: topography of cortical and thalamic afferents. Exp Brain Res 111:215-232.

Sebban C, Tesolin-Decros B, Ciprian-Ollivier J, Perret L, Spedding M (2002) Effects of phencyclidine (PCP) and MK 801 on the EEGq in the prefrontal cortex of conscious rats; antagonism by clozapine, and antagonists of AMPA-, alpha(1)- and 5-HT(2A)-receptors. Br J Pharmacol 135:65-78.

Sohal VS, Zhang F, Yizhar O, Deisseroth K (2009) Parvalbumin neurons and gamma rhythms enhance cortical circuit performance. Nature 459:698-702.

Southwell DG, Froemke RC, Alvarez-Buylla A, Stryker MP, Gandhi SP (2010) Cortical plasticity induced by inhibitory neuron transplantation. Science 327:1145-1148.

Spear LP (2000) The adolescent brain and age-related behavioral manifestations. Neurosci Biobehav Rev 24:417-463.

Staiger JF, Bisler S, Schleicher A, Gass P, Stehle JH, Zilles K (2000) Exploration of a novel environment leads to the expression of inducible transcription factors in barrel-related columns. Neuroscience 99:7-16.
Tanaka DH, Yanagida M, Zhu Y, Mikami S, Nagasawa T, Miyazaki J, Yanagawa Y, Obata K, Murakami F (2009) Random walk behavior of migrating cortical interneurons in the marginal zone: time-lapse analysis in flat-mount cortex. J Neurosci 29:1300-1311.

Tang YP, Shimizu E, Dube GR, Rampon C, Kerchner GA, Zhuo M, Liu G, Tsien JZ (1999) Genetic enhancement of learning and memory in mice. Nature 401:63-69.

Tashiro A, Sandler VM, Toni N, Zhao C, Gage FH (2006) NMDA-receptormediated, cell-specific integration of new neurons in adult dentate gyrus. Nature 442:929-933.

Wichterle H, Garcia-Verdugo JM, Herrera DG, Alvarez-Buylla A (1999) Young neurons from medial ganglionic eminence disperse in adult and embryonic brain. Nat Neurosci 2:461-466.

Xu Q, Cobos I, De La Cruz E, Rubenstein JL, Anderson SA (2004) Origins of cortical interneuron subtypes. J Neurosci 24:2612-2622.

Zhang F, Aravanis AM, Adamantidis A, de Lecea L, Deisseroth K (2007) Circuit-breakers: optical technologies for probing neural signals and systems. Nat Rev Neurosci 8:577-581.

Zipancic I, Calcagnotto ME, Piquer-Gil M, Mello LE, Alvarez-Dolado M (2010) Transplant of GABAergic precursors restores hippocampal inhibitory function in a mouse model of seizure susceptibility. Cell Transplant 19:549-564. 